\title{
DO DOUTORAMENTO PARA O MERCADO DE TRABALHO? O PERCURSO DE INSERÇÃO PROFISSIONAL DE UM GRUPO ALTAMENTE QUALIFICADO
}

\author{
FROM PHD TO THE LABOUR MARKET? \\ THE PROFESSIONAL PATH OF A HIGHLY QUALIFIED GROUP
}

\author{
César Morais \\ Centro Interdisciplinar de Ciências Sociais (CICS.NOVA), Faculdade de Ciências Sociais e Humanas, \\ Universidade NOVA de Lisboa. Av. de Berna, 26 C, 1069-061 Lisboa, Portugal. Email: calm@fcsh.unl.pt
}

\author{
Mariana Gaio Alves \\ Instituto de Educação, Universidade de Lisboa (IE-ULisboa). Alameda da Universidade, 1649-013 Lisboa, \\ Portugal Email: mga@ie.ulisboa.pt
}

\begin{abstract}
Resumo: O número de diplomados de $3^{\circ}$ ciclo no ensino superior português aumentou significativamente desde o início do presente século. Porém, os contornos do percurso profissional pós-doutoramento são ainda pouco conhecidos, o que dificulta um debate informado sobre os efeitos do grau de doutor no mercado de trabalho e sobre o papel dos novos doutorados na produção de conhecimento e na sua transposição da esfera académica para a empresarial. O presente artigo procura contribuir para esse debate, apresentando e discutindo os resultados de uma análise quantitativa aos percursos profissionais de recém-doutorados da Universidade NOVA de Lisboa entre 2010 e 2015, que são contrastados com os dos novos licenciados e mestres dessa instituição. Verifica-se que os doutorados levam vantagem no mundo do trabalho face aos restantes graduados, ainda que principalmente se inscrevam na esfera do ensino superior público enquanto docentes ou investigadores. Também se conclui que existem particularidades nos trajetos profissionais entre ciclos de ensino que importa destacar e monitorizar em investigações subsequentes sobre a inserção profissional de graduados.
\end{abstract}

Palavras-chave: ensino superior, doutorados, inserção profissional.

\begin{abstract}
The number of PhD graduates in Portugal has increased significantly since the beginning of this century. However, the contours of post-doctoral professional paths are still widely unknown, which makes it difficult to have an informed debate about the effects of the $\mathrm{PhD}$ degree in the labour market and the role of doctorates in the production of knowledge and in its transposition from the academic to the corporate sphere. This paper contributes to this debate by presenting and discussing the results of a quantitative analysis of the professional paths of recent $\mathrm{PhD}$ graduates from Universidade NOVA de Lisboa between 2010 and 2015. The professional paths of PhD holders will be compared to the ones of first and second degree graduates of the same institution. The data suggest that PhDs have an advantage in the world of work vis-à-vis other graduates, even though they are mainly enrolled in public higher education as teachers or researchers. It is also concluded that there are particularities in the professional paths between levels of studies that should be highlighted and monitored in subsequent investigations about graduates transitions to work.
\end{abstract}

Keywords: higher education, $\mathrm{PhD}$, transition to work. 


\section{Introdução}

Nas últimas décadas, os percursos escolares têm-se tornado progressivamente mais longos e cada vez mais indivíduos completam o $3^{\circ}$ ciclo do ensino superior, o grau mais elevado da formação académica. Na União Europeia (UE) o ritmo médio de produção de novos doutorados em 2015 ultrapassa o dos Estados Unidos da América ou do Japão (UE, 2018) ${ }^{1}$ animado principalmente por políticas públicas nacionais e supranacionais (Vittorio, 2015) que usualmente atribuem a este grupo altamente escolarizado um papel crucial na criação de conhecimento e na sua transposição para o mundo do trabalho, valorizando o respetivo contributo para o desenvolvimento científico e económico das sociedades contemporâneas (Kyvik e Olsen, 2012). Neste contexto, os percursos de inserção profissional após o doutoramento têm suscitado crescente interesse por parte da comunidade científica (Fischer, 2018; Jones, 2013), nomeadamente procurando averiguar se, e como, se associam à produção e transmissão de conhecimento e até que ponto são afetados pelo desemprego, precariedade laboral ou desajustamento profissional (Enders, 2004), fenómenos que se tornam cada vez mais comuns entre a globalidade dos graduados em espaço europeu (Allen e Velden, 2007; Theicher, 2009).

Em Portugal, o número de doutoramentos tem vindo a aumentar de forma significativa e consistente desde o início deste século e, se no ano letivo de 2000/2001 o número de novos doutorados se quedou aquém dos 600 (DGEEC, 2019), no de 2015/2016 já excedia os 2300 (DGEEC, 2016). Apesar deste notável crescimento, os contornos do percurso de inserção profissional das novas coortes de doutorados são ainda pouco escrutinados e raras vezes surgem confrontados com os de novos licenciados ou mestres, o que dificulta um debate informado sobre o valor do grau de doutor no mercado de trabalho português face aos outros graus académicos ou sobre o papel dos novos doutorados na produção de conhecimento e na sua transposição para o mundo do trabalho.

Este artigo visa contribuir para esse debate, inscrevendo-se, portanto, no campo de investigação sobre a inserção profissional de graduados (Marques e Alves, 2010). A análise toma por objeto de estudo os recém-doutorados de uma universidade pública lisboeta e almeja responder a quatro questões interligadas: i) qual o seu perfil educacional e como se distingue dos de licenciados e mestres? ii) qual o seu percurso profissional e como se distingue dos de licenciados e mestres? iii) quais os seus destinos profissionais mais prováveis? iv) e quais os fatores de clivagem no percurso profissional dos doutorados? Estas questões são abordadas numa perspetiva quantitativa e evolutiva, ou seja, observam-se os resultados de cinco inquirições por questionário a cinco coortes consecutivas de novos graduados entre os anos de 2010 
e de 2015. Trata-se de um período temporal atravessado por um cenário económico globalmente negativo no qual a situação no mercado de trabalho se degradou sobremaneira, especialmente para os mais jovens que procuravam iniciar o seu trajeto laboral (Costa e Caldas, 2013).

\section{Inserção profissional de recém-doutorados em Portugal: Pontos de partida possíveis}

O relativo desconhecimento sobre os percursos de inserção profissional de recém-doutorados em Portugal advém sobretudo da escassez de fontes de informação que permitam, simultaneamente, acompanhar a sua evolução ao longo do tempo e compará-los com os de outras populações de diplomados e não-diplomados, nacionais ou internacionais.

Esta lacuna surge flagrante nas estatísticas oficiais do emprego divulgadas pelo Instituto Nacional de Estatística (INE) pois nelas se agrupam licenciados, mestres e doutores numa única categoria dado não possuírem o alcance (amostral) necessário para singularizar cada um deles. Por outro lado, desde 2006 que a Direção Geral de Estatísticas do Ensino Superior (DGEES) realiza trienalmente o inquérito por questionário Careers of Doctorate Holders $(\mathrm{CDH})^{2}$. O CDH segue uma metodologia harmonizada internacionalmente e observa um procedimento censitário que visa inquirir todos os doutorados residentes em Portugal com menos de 70 anos. Apesar do rigor e qualidade do $\mathrm{CDH}$, os seus resultados foram ainda pouco analisados pela comunidade científica nacional e aqueles que são divulgados raramente distinguem novos doutorados de doutorados experientes. Esta distinção é particularmente importante no estudo da inserção profissional, uma vez que a extensão do período que medeia desde a obtenção do diploma se afigura muito relevante para o tipo de posição ocupada no mercado de trabalho (Alves, 2010; Chaves, Morais e Nunes, 2009). O CDH também não permite uma comparação entre graduados de vários ciclos uma vez que observa doutorados e não existem dados idênticos para licenciados ou mestres. Já entre a crescente rede de instituições de ensino superior universitário em Portugal que oferecem formações de $3^{\circ}$ ciclo, unicamente três divulgaram publicamente dados sobre a situação profissional da globalidade dos (seus) diplomados (licenciados, mestres e doutores) ao longo da presente década, nomeadamente, Instituto Superior Técnico (OEIST, 2013), a Universidade de Aveiro (OPSDUA, 2018) e a Universidade Nova de Lisboa (OBIPNOVA, 2017) e apenas esta última o faz com periodicidade anual. Não obstante a sua qualidade intrínseca, estes dados de âmbito institucional dificilmente permitem uma consulta cumulativa ou comparada que englobe 
várias universidades, pois as inquirições resultam de diferentes procedimentos amostrais, mobilizam indicadores desiguais e observam períodos temporais distintos entre momento da graduação e da inquirição. Ainda assim, sobressai nos dados das várias instituições que a inscrição dos doutorados no mercado de trabalho tende a ser mais célere e recompensadora do que a dos restantes diplomados.

Destaque-se um estudo que analisou comparativamente a designada empregabilidade de bacharéis, licenciados, mestres e doutores a partir dos Quadros de Pessoal do ex-Ministério do Trabalho e Segurança Social, mas apenas durante a primeira década deste século (Cardoso, Escária, Ferreira, Madruga, Raimundo e Varanda, 2012). Apesar de englobarem um conjunto limitado de indicadores e se referirem apenas aos trabalhadores por conta de outrem, estes dados permitem verificar que o desemprego é menos frequente entre doutorados e que estes são melhor remunerados do que os licenciados ou os mestres (Cardoso, Escária, Ferreira, Madruga, Raimundo e Varanda, 2012, pp. 102-103), sugerindo, portanto, que nestas duas dimensões o doutoramento é efetivamente valorizado no mercado de trabalho português. Está ainda por determinar como é que essa mais-valia evoluiu na presente década, dado que para a globalidade dos jovens graduados portugueses o ciclo económico negativo já instalado em 2010 (Costa e Caldas, 2013) traduziu-se no aumento dos níveis de inatividade (económica), desemprego e trabalho temporário, assim como na diminuição dos rendimentos obtidos através do trabalho, particularmente até 2014, pois em 2015 já se observavam alguns sinais de retoma nestes indicadores (Alves, Morais e Chaves, 2017).

Não obstante a maioria dos jovens graduados do ensino superior em Portugal se inscrever em posições profissionais mais qualificadas e qualificantes do que aqueles que possuem menores níveis de instrução (Ferreira, 2017), a análise sociológica tem salientado que a quantidade e qualidade dos seus empregos são condicionadas por diversos fatores pessoais, sociais e contextuais (Raffe, 2014), nomeadamente, género (Casaca, 2012), área de formação académica (Cardoso, Escária, Ferreira, Madruga, Raimundo e Varanda, 2012), experiência de trabalho prévia à graduação (Monteiro, Almeida e Aracil, 2016) e nível de instrução e classe social dos pais (Chaves e Morais, 2014). Estas investigações não permitem porém singularizar a situação dos doutorados, dissolvendo-se assim qualquer particularidade desses numa categoria geral que integra essencialmente licenciados e mestres. Do ponto de vista da compreensão sociológica sobre as dinâmicas da inserção profissional de graduados, reveste-se de importância capital verificar se estes fatores de clivagem se mantêm ao considerar separadamente cada um dos ciclos de ensino.

No que concerne ao papel dos novos doutorados em Portugal na produção de conhecimento, convém desde logo notar que o nível de qualificações de 
investigadores e de docentes do ensino superior português ainda se afirma particularmente reduzido quando comparado internacionalmente (Horta e Hasanefendic, 2015; Santos, Horta e Heitor, 2016), mesmo que o atual quadro legal da carreira de investigação científica (Decreto de lei n. ${ }^{\circ} 124$ /99) e de docência nas universidades (Decreto de lei n. ${ }^{0} 205 / 2009$ ) e nos politécnicos (Decreto-Lei n. ${ }^{\circ}$ 207/2009) estabeleça o doutoramento como requisito de acesso. Esta lacuna qualificacional assinala um importante espaço profissional de acolhimento para os novos doutorados com impacto no desenvolvimento científico nacional, conforme se pode verificar pela correlação entre o crescimento do número de novos doutorados em Portugal e o aumento quer do número de publicações científicas (indexadas na Web of Science), quer do seu fator de impacto, entre 2004 e 2011 (Santos, Horta e Heitor, 2016). Mesmo que o recente período de crise económica tenha dificultado o acesso e erodido as condições de trabalho nas carreiras de investigação (Cairns, Cuzzocrea e Briggs, 2017) e de docência (Cardoso, Carvalho e Cideira, 2018), os resultados das várias inquirições CDH revelam que a esmagadora maioria dos doutorados residentes em Portugal se inscreve nessa esfera académica (Cotrim e Duarte, 2015; DGEEC, 2017; GPARI, 2009, 2011), ainda que não precisem se esta forte aliança também se verifica entre as coortes de doutorados mais recentes.

Também a pesquisa sobre a relação entre os percursos de inserção profissional de doutorados e a disseminação de conhecimento se afirma particularmente escassa no contexto português. Contudo, e como se referiu antes, as várias inquirições CDH assinalam uma parcela exígua de doutorados em Portugal a trabalhar fora da esfera académica, o que, desde logo, indicia pouca vitalidade nessa transmissão de conhecimento. Note-se também que os doutoramentos em ambiente empresarial, orientados para a promoção de articulações entre academias e empresas, são raros em Portugal e, segundo estudo recente, o seu desenvolvimento curricular ainda carece de uma maior articulação entre os agentes académicos e empresariais, mesmo que já se distinga dos programas doutorais tradicionais (Cardoso, Tavares e Sin, 2019). Por último, destaque-se que a presença de doutorados na administração pública é também diminuta, como se verifica se considerarmos que, em 2014, apenas $9 \%$ desses trabalhadores possuíam um doutoramento ou um mestrado, mesmo incluindo aqui as classes profissionais dos professores e dos médicos (Santos, Horta e Heitor, 2016).

\section{Metodologia}

Perante a impossibilidade de responder aos objetivos propostos a partir de dados representativos da população portuguesa, toma-se como universo de observação os 
Tabela 1 Universo, Amostra, Taxa de Resposta e Margem de Erro Amostral para as inquirições do OBIPNOVA a graduados da NOVA entre 2010 e $2015^{(1)}$

\begin{tabular}{l|l|r|r|r|r|r|r}
\hline \multicolumn{2}{c}{} & \multicolumn{6}{c}{ Anos } \\
\cline { 3 - 8 } \multicolumn{2}{c|}{} & 2010 & 2011 & 2012 & 2013 & 2014 & 2015 \\
\cline { 3 - 8 } Licenciados & Universo (N) & 1.500 & 1.112 & 1.287 & 1.330 & 1.484 & 1.282 \\
& Amostra (n) & 1.010 & 769 & 880 & 909 & 1.027 & 724 \\
& Taxa de Resposta (\%) & 67,3 & 69,2 & 68,4 & 68,3 & 68,4 & 56,5 \\
& Margem de Erro (\%)* & 1,8 & 2,0 & 1,9 & 1,8 & 1,7 & 2,4 \\
\hline \multirow{4}{*}{ Mestres } & Universo (N) & 1.432 & 1.375 & 1.664 & 1.846 & 1.820 & 1.620 \\
& Amostra (n) & 1.060 & 959 & 1.131 & 1.220 & 1.200 & 844 \\
& Taxa de Resposta (\%) & 74,0 & 69,7 & 68,0 & 66,1 & 65,9 & 52,1 \\
& Margem de Erro (\%)* & 1,5 & 1,7 & 1,6 & 1,6 & 1,7 & 2,3 \\
\hline \multirow{3}{*}{ Doutores } & Universo (N) & 165 & 173 & 199 & 192 & 238 & 196 \\
& Amostra (n) & 82 & 103 & 130 & 122 & 160 & 100 \\
& Taxa de Resposta (\%) & 49,7 & 59,5 & 65,3 & 63,5 & 67,2 & 51,0 \\
& Margem de Erro (\%)* & 7,7 & 6,1 & 5,1 & 5,4 & 4,4 & 6,9 \\
\hline
\end{tabular}

(1) Os dados relativos aos licenciados e mestres inquiridos pelo OBIPNOVA entre 2010 e 2015 foram também analisados pelos autores a partir de uma perspetiva de género (Alves e Morais, no prelo) e, portanto, a porção desta tabela relativa a esses graduados foi aí também utilizada. Nesse contexto foram ainda analisados os dados sobre o contingente feminino entre licenciados e mestres que, em moldes distintos e a par com os relativos aos doutorados, se observam igualmente na presente análise.

* Considerando um intervalo de confiança de $95 \%$ e assumindo a hipótese pessimista $[1,96 * \sqrt{ }(1-n / N) *(0,25 / n)]$ Fonte: OBIPNOVA.

graduados da Universidade NOVA de Lisboa (NOVA). Os dados sob escrutínio são recolhidos anualmente, desde 2010, pelo Observatório de Inserção Profissional de Diplomados da NOVA (OBIPNOVA) através de uma inquirição por questionário a graduados de $1^{\circ}, 2^{\circ}$ (incluindo mestrados integrados) e $3^{\circ}$ ciclo da NOVA que terminaram os seus cursos cerca de um ano antes. A coleção de dados entretanto criada permite uma análise evolutiva do perfil educacional destes graduados e da sua situação profissional entre 2010 e 2015, atendendo comparativamente aos seus distintos graus académicos. A significância estatística das diferenças entre ciclos de ensino foi testada através da realização de testes de Qui-quadrado ou One-way Anova, considerando a adequação dos seus pressupostos às características dos indicadores testados.

As inquirições do OBIPNOVA têm por base amostras aleatórias simples para cada ano e ciclo de ensino com margens de erro amostral que não ultrapassam os $2 \%$ nos $1^{\circ}$ e $2^{\circ}$ ciclos e que variam entre $4,4 \%$ e $7,7 \%$ no caso do $3^{\circ}$ ciclo, considerando um intervalo de confiança de $95 \%$. As taxas de resposta anuais rondam os $70 \%$ tanto entre licenciados como entre mestres e oscilam em torno dos $60 \%$ entre doutores. Tal como sucede em território nacional, o prolongamento das carreiras escolares também surge visível na NOVA, pois ainda que o número global de diplomados se mantenha relativamente estável nas seis coortes analisadas, entre elas 
a fileira de licenciados reduz cerca de $17 \%$ enquanto o número de mestres cresce mais de $11 \%$ e o de doutorados aumenta quase $17 \%$ (Tabela 1 ).

\section{O perfil educativo dos graduados da NOVA}

No que concerne à evolução do perfil educativo dos diplomados na NOVA entre 2010 e 2015 sobressai desde logo a sua progressiva e transversal feminização, não existindo diferenças estatisticamente significativas entre ciclos a esse nível (Figura 1) ${ }^{3}$.

Note-se porém que, na maioria dos anos, o contingente feminino entre doutorados supera os $60 \%$, surgindo portanto mais notório do que entre licenciados ou mestres, pois nestes casos apesar de sempre maioritário nunca alcança essa fasquia. Por outro lado, ainda que a presença feminina se torne mais evidente ao longo do tempo em todos os ciclos académicos, esse crescimento surge mais acelerado entre os doutorados aumentando mais de $17 \%$ entre 2010 e 2015, face a um acréscimo de $8,4 \%$ no caso dos licenciados e de apenas 1,5\% no dos mestres. Este processo de feminização dos graduados da NOVA, especialmente ao nível dos doutoramentos, também se verifica na globalidade das instituições do ensino superior português, em que a percentagem de mulheres entre graduados em 2015 é de 59,5\% ou de 52,3\% se considerarmos apenas os doutorados (DGEEC, 2016) e reflete o maior sucesso dos percursos escolares e académicos das mulheres em Portugal.

Em termos etários, não causa surpresa que a idade tenda a aumentar consoante ascendemos na hierarquia dos graus académicos, uma relação com significância estatística (Figura 2) ${ }^{4}$.

Assim, ao longo de todo o período temporal em análise, a idade dos doutorados ronda os 40 anos em média, enquanto entre licenciados esse valor ronda os 25 anos e no caso dos mestres os 29 anos. No entanto, torna-se visível uma ligeira tendência para a redução destes valores médios entre 2010 e 2015. O facto dos graduados da NOVA serem, em média, cada vez mais jovens, revela que os seus percursos escolares e académicos tendem a ser cada vez mais lineares, ou seja, torna-se cada vez mais frequente que a passagem entre os vários níveis de escolaridade decorra sem quaisquer interrupções ou reprovações. Acresce que estes percursos também se tornam progressivamente mais dedicados, como se pode verificar através da figura 3, onde sobressai a diminuição progressiva da parcela de trabalhadores estudantes em todos os ciclos de ensino apesar dos pesos estatisticamente diferentes que essa situação representa em cada um deles ${ }^{5}$.

De facto, mesmo que a maioria dos doutorados procure conciliar estudos com trabalho, o que remete para percursos de formação académica não exclusivos, sobressai que entre 2010 e 2015 essa situação se tem vindo a tornar menos frequente e, 


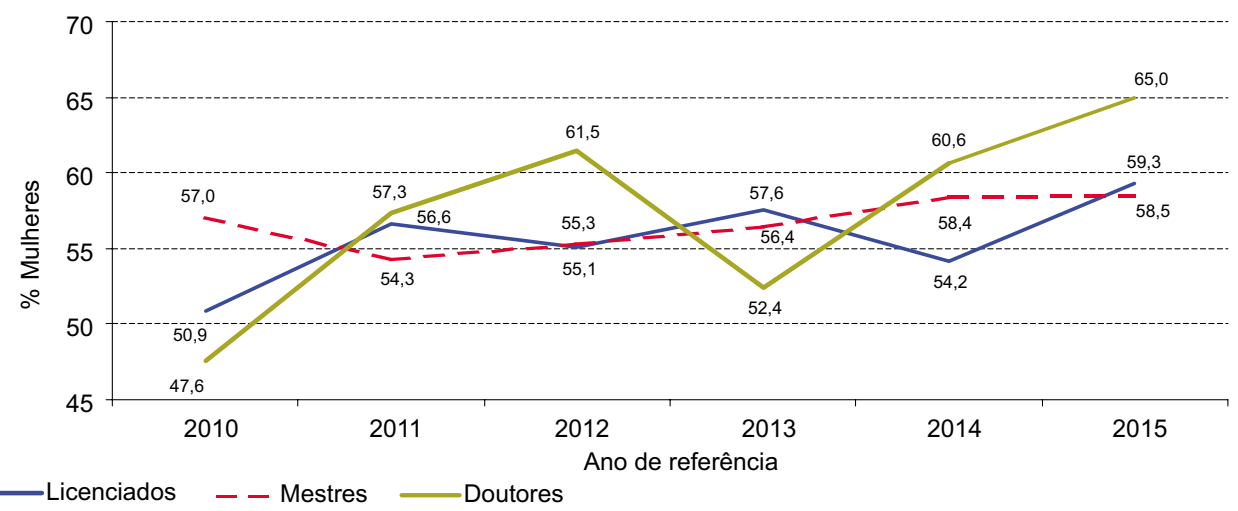

Figura 1 Presença feminina entre graduados da NOVA de 2010 a 2015 (\%) Fonte: OBIPNOVA.

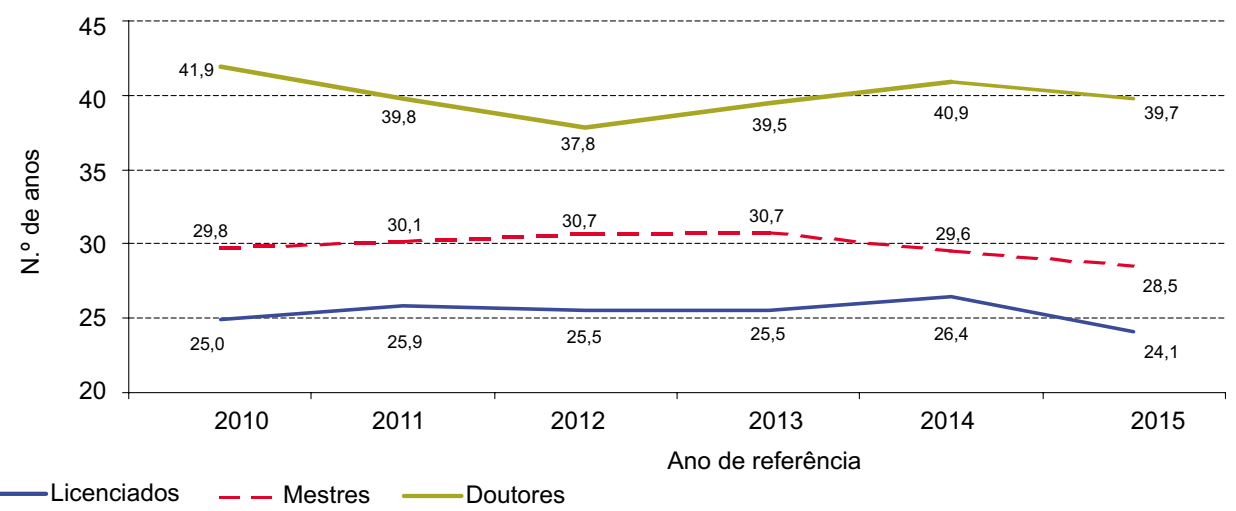

Figura 2 Idade média dos graduados da NOVA no momento de inquirição (anos)

Fonte: OBIPNOVA.

portanto, a parcela daqueles que realizam o seu doutoramento em exclusividade tem vindo a aumentar. Esta progressiva vulgarização de carreiras escolares dedicadas surge também patente entre licenciados e mestres: ainda que o peso dos trabalhadores estudantes seja bastante inferior no primeiro caso, em ambos reduz de forma notória ao longo dos 6 anos em análise, respetivamente, de $52,5 \%$ para $38,5 \%$ e de $62,2 \%$ para $46,2 \%$. Mesmo que, como detalharemos adiante, esta redução da parcela de trabalhadores estudantes seja em parte motivada por maiores dificuldades em obter um emprego, a continuidade desta tendência mesmo em anos de retoma do emprego indicia a sua consolidação enquanto estratégia perante o ensino superior. 


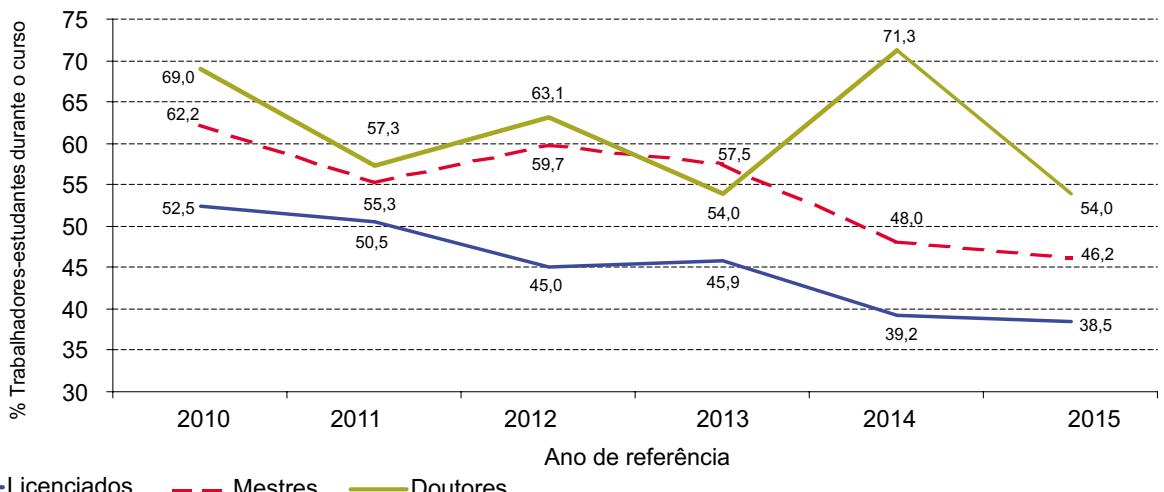

Figura 3 Trabalhadores-estudantes durante o curso entre graduados da NOVA de 2010 a 2015 (\%) Fonte: OBIPNOVA.

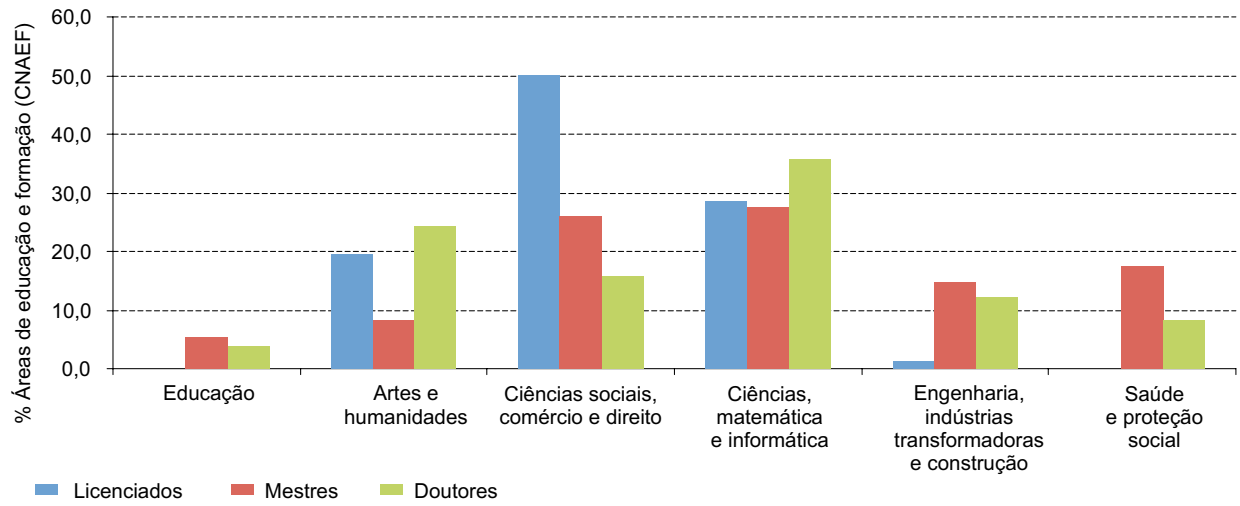

Figura 4 Áreas de Educação e Formação (CNAEF) dos graduados da NOVA de 2010 a 2015 (\%) Fonte: OBIPNOVA.

Entre 2010 e 2015 apenas se registam variações mínimas no peso de cada área de educação e formação dos graduados da NOVA, o que reflete a estabilidade da oferta formativa desta universidade e retira pertinência a uma análise evolutiva. No entanto, as diferenças entre ciclos de ensino depois de agrupados os vários anos em análise revestem-se de importância estatística e justificam ser enquadradas nesta análise (Figura 4)6.

Assim, mesmo que a maioria destes graduados se concentre nas áreas da "Ciências, matemática e informática" e das "Ciências sociais, comércio e direito", esta última surge particularmente vincada entre licenciados, enquanto as "Artes e 
humanidades" ganham maior expressão entre doutorados. Note-se, ainda, que nas áreas da "Educação", "Engenharia, indústrias transformadoras e construção" e na "Saúde e proteção social", o grau requerido para acesso à profissão de professor, engenheiro ou médico passou, com o processo de Bolonha, a ser o mestrado e, portanto, neste trio de áreas existem essencialmente mestres e doutorados.

\section{A situação profissional dos graduados da NOVA um ano após a sua graduação}

Um ano após terminarem o seu curso poucos doutorados não estão a trabalhar, o que se traduz numa taxa de emprego que ronda ou supera os $90 \%$ na maioria dos anos em análise, ainda que, e com algumas oscilações, essa taxa revele uma tendência global para recuar ligeiramente entre 2010 (91,7\%) e 2015 (88\%) (Figura 5).

A taxa de emprego dos mestres também se afirma sempre bastante elevada, ainda que aquém da dos doutorados - rondando os $85 \%$-, reduzindo igualmente de forma ligeira ao longo dos 6 anos sob escrutínio, especialmente até 2013. A evolução desta taxa entre os licenciados distingue-se sobremaneira da dos restantes graduados, quer porque o seu valor médio anual é bastante mais reduzido aquém de 50\% na maioria dos anos - , quer pela sua notória redução entre 2010 e 2015, resultado de uma queda abrupta até 2012 apenas minimizada nos anos subsequentes. Com efeito, assomam diferenças estatisticamente significativas entre ciclos de ensino no que concerne à sua situação perante a atividade ${ }^{7}$.

A diminuição transversal das taxas de emprego relaciona-se principalmente com a grave crise económica que afetou o mercado de trabalho em Portugal neste período e que, justamente, mais se fez sentir nos primeiros anos em análise. Por outro lado, os diferentes níveis e evoluções que esta taxa assume entre ciclos de ensino revelam que a crise quantitativa no emprego afetou principalmente os licenciados e surge minimizada, a partir de 2013, para todos os diplomados. Acrescente-se que a maioria dos licenciados que não possuem um emprego permanece na esfera académica para prolongar os seus estudos além do $1^{\circ}$ ciclo, seja de forma dedicada ou enquanto procuram um emprego. Entre mestres e doutorados, o prolongamento de estudos é menos frequente mas, ainda assim, explica parte significativa das situações de não-trabalho.

Os níveis esmagadores de emprego dos doutorados resultam quase exclusivamente, e em qualquer dos anos em análise, de diversas situações profissionais relacionadas com a docência no ensino superior ou a investigação científica. Destaque-se também que a maioria dos doutorados investigadores possui bolsas de pós-doutoramento ou ao abrigo de projetos de investigação. A incidência de bolseiros no total de doutorados empregados cresce entre 2010 (26\%) e 2013 (36,5\%) 


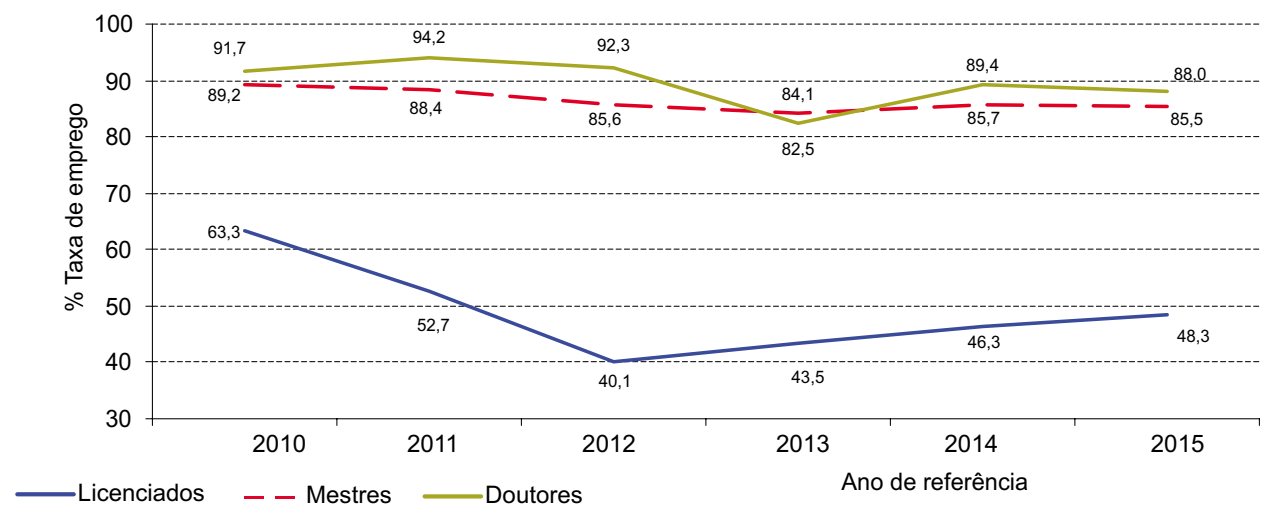

Figura 5 Taxa de emprego entre os graduados da NOVA de 2010 a 2015 (\%) Fonte: OBIPNOVA.

ainda que depois reduza em 2014 (27,3\%) e 2015 (21,6\%). Esta evolução, cotejada com a da taxa de emprego, revela que estas bolsas na esfera da produção científica, não obstante o seu carácter temporário, assumiram especial importância entre os recém-doutorados durante o período de mais acentuada crise económica, o que certamente contribuiu para minimizar a quebra no emprego durante esses anos. Já o rápido recuo dessas bolsas em 2014 e 2015 justifica em parte a redução da taxa de emprego dos doutorados entre esses anos de retoma global.

Entre os diplomados empregados encontramos uma parcela diminuta que trabalha fora de Portugal. Este indicador só está disponível a partir de 2011, mas permite aferir que, apesar de constantes flutuações, o peso dos que emigraram para trabalhar tende a aumentar progressivamente de 2010 até 2015 em todos os ciclos de ensino e também a aproximar-se entre ciclos ao longo desses anos (Figura 6) ${ }^{8}$.

Ainda que o peso dos doutorados empregados fora de Portugal aumente apenas 0,8\% entre 2011 e 2015, estes graduados são os que mais emigram e no último desses anos representam já $8 \%$ daqueles que estão empregados. Entre licenciados e mestres o peso da emigração é menor rondando os $6 \%$ em 2015, ainda que o seu aumento seja bastante mais evidente, atingindo os $3,3 \%$ entre licenciados e $4,9 \%$ entre os mestres e aproximando-os dos valores registados entre os doutorados. Trata-se de um crescente fluxo migratório também visível a nível nacional, o qual tem vindo a ser associado à falta de oportunidades de emprego ou de carreira em Portugal (Gomes, 2015). Se recuperarmos a evolução das taxas de emprego em cada ciclo, torna-se expectável que os licenciados emigrem principalmente em busca de um emprego e que os mestres e doutorados emigrem sobretudo em busca de melhores condições de carreira, mas não dispomos de dados que permitam averiguar inequivocamente as suas razões para emigrar. 


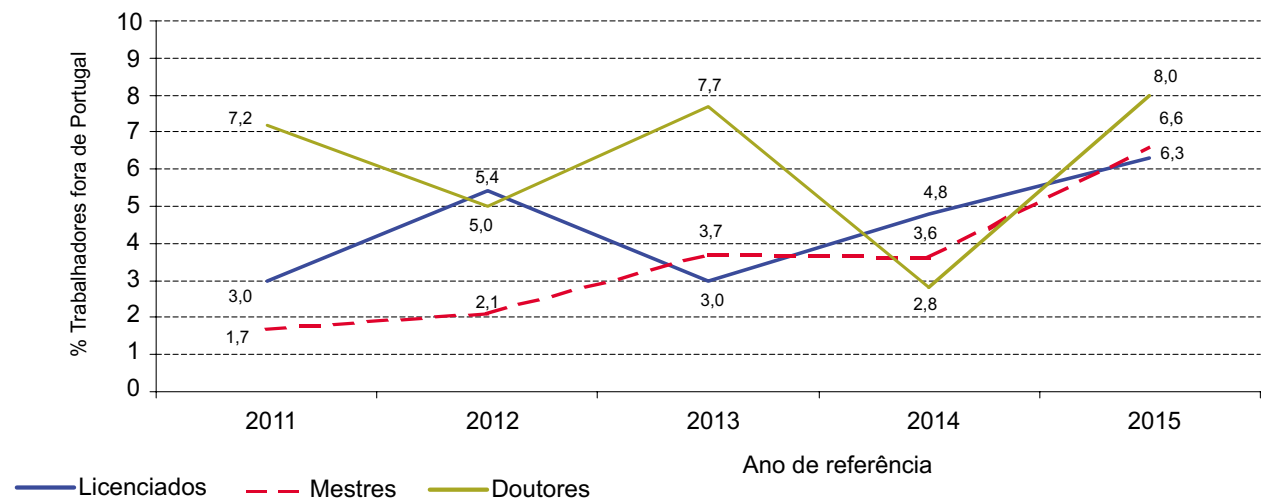

Figura 6 Trabalhadores fora de Portugal entre os graduados da NOVA de 2011 a 2015 (\%) Fonte: OBIPNOVA.

No que concerne à qualidade do emprego, analisa-se primeiro a adequação entre o emprego dos graduados em estudo e a sua área de formação a partir de um exercício subjetivista (Chaves, Morais e Nunes, 2009), ou seja, pediu-se aos próprios graduados que avaliassem esse ajustamento utilizando uma escala com 10 valores que se baliza entre a total desadequação e a total adequação. Essas respostas foram depois dicotomizadas considerando que as avaliações inferiores a 6 pontos correspondiam a uma situação de desajustamento profissional e que as avaliações iguais ou superiores a 6 pontos traduziam uma situação de ajustamento. Este cálculo permite verificar que uma clara maioria dos doutorados considera a atividade profissional que possui ajustada à sua área de formação académica, correspondendo a uma parcela que entre 2010 e 2015 se mantém sempre elevada ainda que o seu peso oscile bastante de ano para ano, variando entre os $81,5 \%$ e os $93,2 \%$. Esta perceção generalizada de elevado ajustamento profissional entre os doutorados não será alheia à sua forte aliança com a docência académica e a investigação científica, indiciando assim que nessas esferas as suas competências são desejadas e, se recuperarmos os elevados níveis de emprego ao longo deste período, são também enquadráveis (Figura 7).

Na leitura da figura 7 sobressai ainda que existem mais doutorados que percecionam a sua situação profissional como ajustada à sua área de formação do que mestres e, especialmente, do que licenciados: dissemelhanças entre ciclos que na maioria dos anos são relevantes estatisticamente. Com efeito, o caso dos mestres este indicador ronda os $80 \%$ entre 2010 e 2015 e parece revelar alguma estabilidade, enquanto no caso dos licenciados o ajustamento profissional surge em quebra quase contínua passando de 72,6\% em 2010 para 63,9\% em 2015 . 


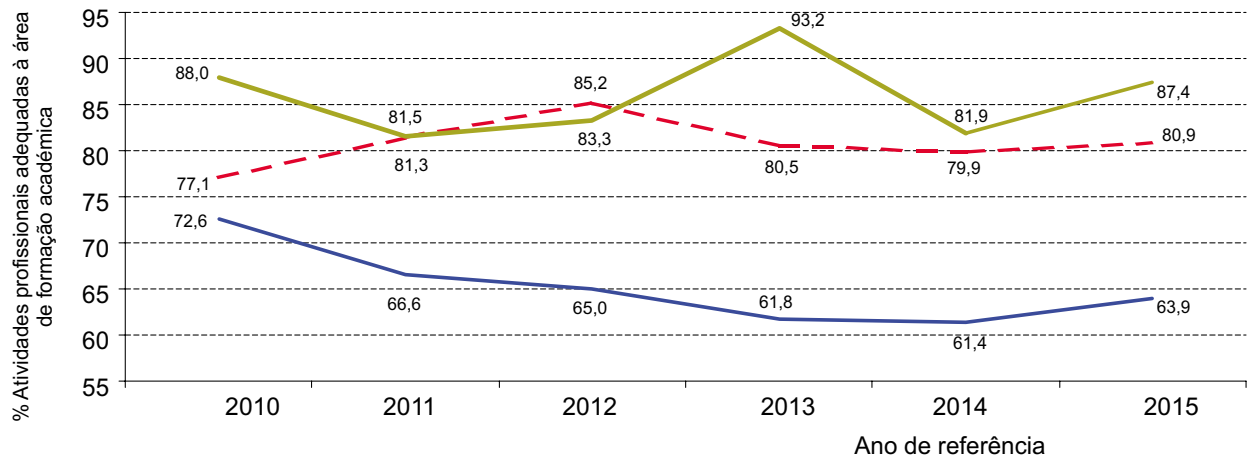

—Licenciados $\quad-$ Mestres Doutores

Figura 7 Adequação das atividades profissionais à área de formação académica entre os graduados da NOVA de 2010 a 2015 (\%)

Fonte: OBIPNOVA.

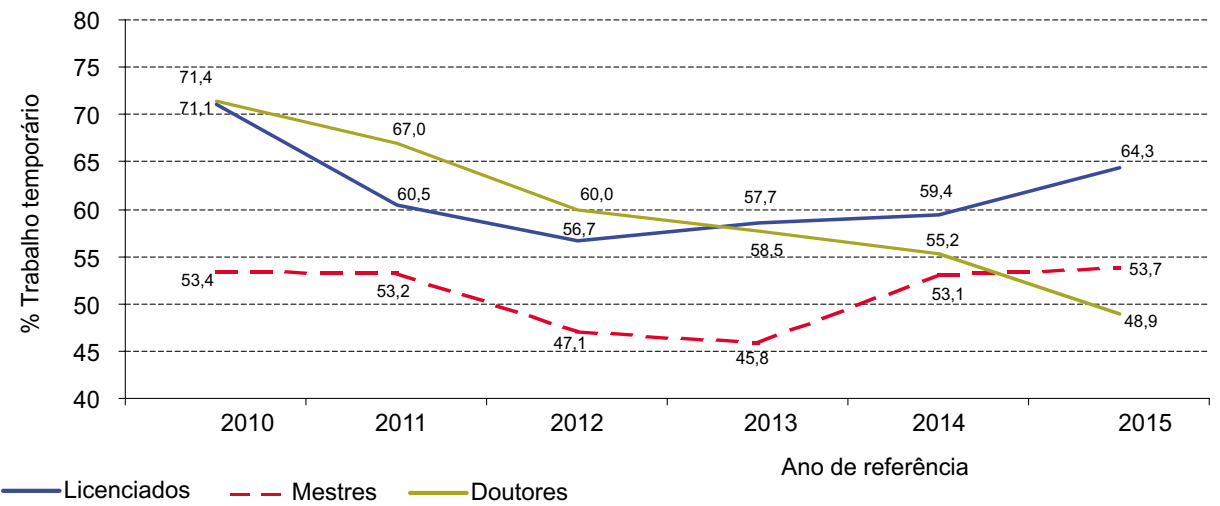

Figura 8 Trabalho temporário entre os graduados da NOVA de 2010 a 2015 (\%)

Fonte: OBIPNOVA.

Os graduados com um trabalho temporário, isto é, todos aqueles que não possuem um contrato de trabalho ou que possuem um vínculo contratual com termo previsto, assumem uma expressão notável em todos os ciclos de ensino mas com níveis e tendências evolutivas distintas que se revestem de significância estatística (Figura 8) ${ }^{10}$.

Entre os doutorados, o trabalho temporário representa mais de $71 \%$ do total dos empregados em 2010, porém perde progressivamente importância desde então, não englobando mais de $49 \%$ dos empregados em 2015. Os licenciados com trabalhos temporários também superam os 71\% em 2010, uma parcela que diminui 


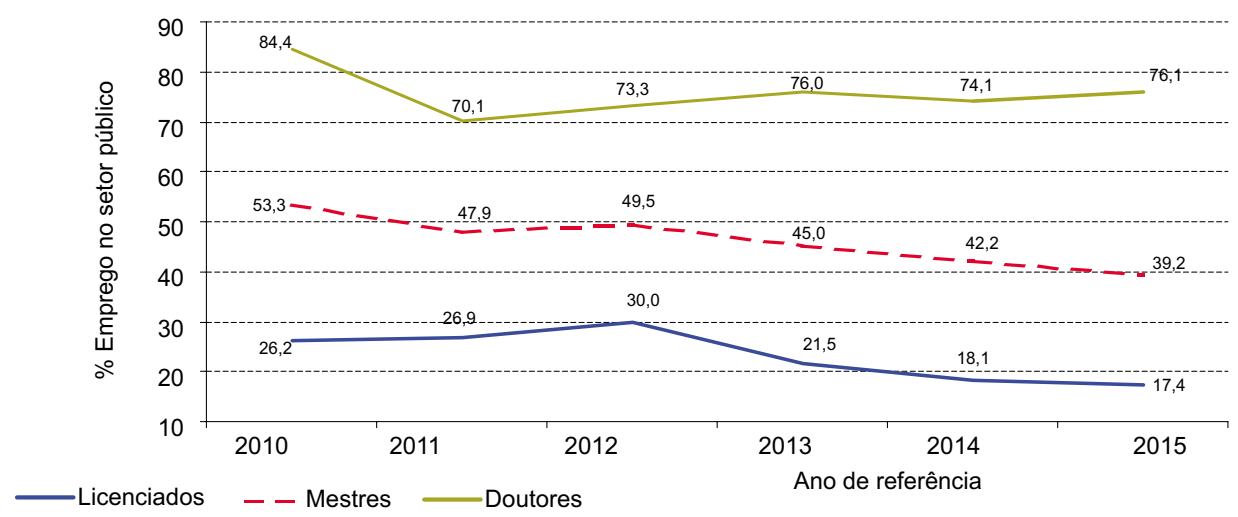

Figura 9 Emprego no setor público entre os graduados da NOVA de 2010 a 2015 (\%) Fonte: OBIPNOVA.

abruptamente até 2012 para depois aumentar de forma contínua até 2015 atingindo os $64 \%$. O trabalho temporário é menos expressivo entre os mestres, ainda que permaneça maioritário rondando os $53 \%$ do total do emprego na maior parte dos anos e ficando aquém dessa marca apenas em 2012 e 2013.

Sabendo que durante o período em análise o trabalho temporário se encontra largamente disseminado e em expansão entre a globalidade dos jovens graduados portugueses (Alves, Morais e Chaves, 2017), causa alguma surpresa que este diminua substancialmente e de forma contínua entre os doutorados da NOVA. A redução no número de bolseiros assinalada antes certamente contribuirá para esta evolução, mas a análise da figura 9, relativo à parcela de graduados inscritos no setor público de emprego, permite avançar uma segunda hipótese explicativa para a diminuição do trabalho temporário entre estes doutorados.

Com efeito, não obstante o recuo global do emprego no setor público durante o período temporal em análise, a parcela de doutorados da NOVA que nele se inscreve é sempre esmagadora e, apesar de sofrer uma quebra notória entre 2010 e 2011, respetivamente de $84 \%$ para $70 \%$, aumenta depois até se cifrar em 76,1\% em 2015. Assim, o referido recuo do setor público de emprego apenas se torna visível entre os restantes graduados, pois se em 2010 mais de $26 \%$ dos licenciados e $53 \%$ dos mestres trabalhavam na esfera pública em 2015 essas parcelas reduzem até, respetivamente, $17 \%$ e $39 \%$. Em suma, o número de diplomados inscritos no setor público é significativamente diferente de acordo com o ciclo de estudos ${ }^{11}$.

Ainda que existam empregos temporários no setor público, como no caso dos doutorados bolseiros, é possível afirmar que entre o crescente número de doutorados 


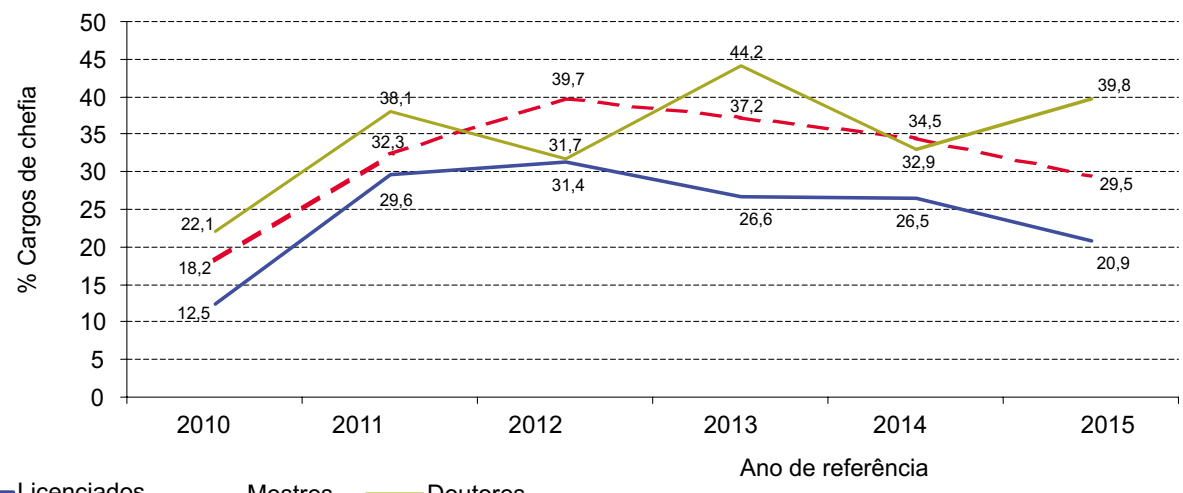

Figura 10 Cargos de chefia entre os graduados da NOVA de 2010 a 2015 (\%) Fonte: OBIPNOVA.

da NOVA que nele se inscrevem, quer como docentes, quer como investigadores, essa situação se tem vindo a tornar menos frequente, enquanto entre os licenciados e mestres que maioritariamente se inscrevem no setor privado o trabalho temporário se tem banalizado. Posto isto, sobressai que a crescente aliança dos doutorados ao setor público os tem vindo a proteger de uma maior insegurança contratual.

Por outro lado, esta estreita relação limita o alcance da transferência social do conhecimento altamente especializado destes doutorados, que surgem pouco presentes enquanto trabalhadores no tecido empresarial privado, especialmente se considerarmos que muitos são igualmente docentes ou investigadores. Acresce ainda que os empregados na administração pública também se revelam absolutamente residuais em qualquer dos anos sob escrutínio, apesar da diagnosticada carência qualificacional a este nível (Santos, Horta e Heitor, 2016). Assim, considerando que a maioria dos doutorados se inscreve no âmbito da docência universitária e da investigação científica, torna-se inegável o seu papel enquanto produtores de conhecimento e também o seu contributo para o reforço das qualificações dos corpos docentes e de investigação.

Os cargos de chefia, isto é, posições profissionais onde se verifica ou se atribui trabalho a outros, têm vindo a tornar-se cada vez mais frequentes entre os doutorados e, ainda com oscilações, aumentam de 22,1\% em 2010 para 39,8\% em 2015. Esses cargos são ligeiramente menos frequentes entre mestres e, especialmente, licenciados, sendo que estas diferenças tendem a agudizar-se ao longo dos anos. Acresce que, entre mestres e licenciados, as posições de chefia apenas se tornam mais frequentes até 2012, pois a partir desse ano a sua frequência diminui quedando-se em 2015 por $29,5 \%$ no primeiro caso e 20,9\% no segundo (Figura 10)12. 


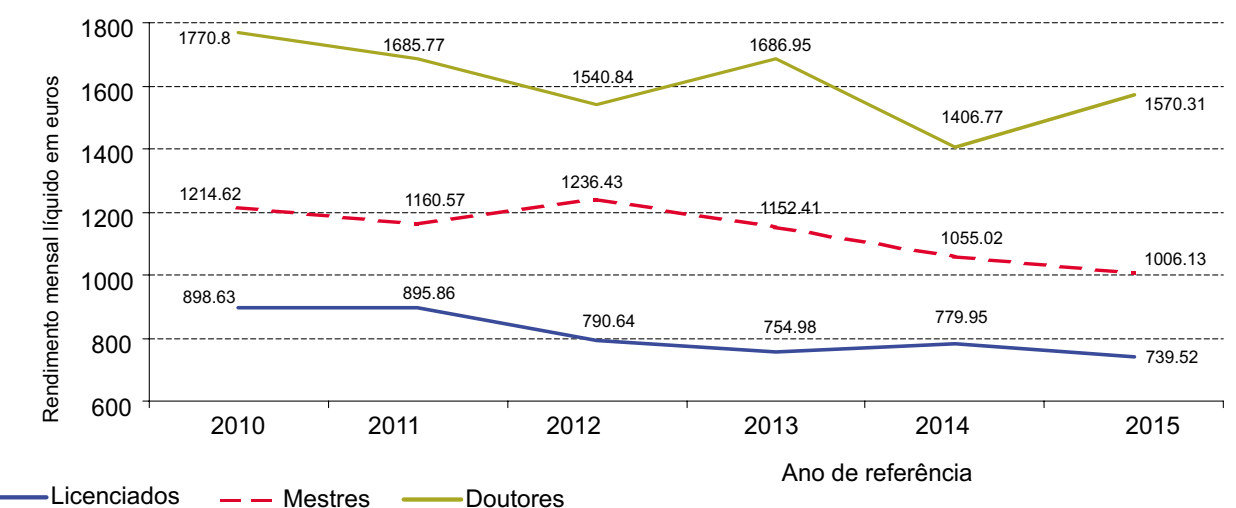

Figura 11 Rendimento mensal líquido médio entre os graduados da NOVA de 2010 a 2015 (euros) Fonte: OBIPNOVA.

A evolução do valor médio dos rendimentos salariais líquidos entre 2010 e 2015 revela um cenário de pauperização generalizada, mas com diferenças assinaláveis e estatisticamente significativas entre os vários ciclos de ensino. Durante esse período os doutorados acumulam perdas menores nos seus rendimentos - cerca de $12 \%$ - do que os licenciados ou mestres - em ambos os casos rondam os 18\% - e em 2015 a sua remuneração líquida média (1570 euros) mais que dobra a dos licenciados (738 euros) e supera em mais de $1 / 3$ a dos mestres (1006 euros). Esta redução transversal dos rendimentos salariais líquidos, além de refletir uma progressiva desvalorização do valor do trabalho, também espelha o crescente aumento do peso dos impostos durante os anos em análise. Por outro lado, as flagrantes diferenças nos valores remuneratórios entre ciclos de ensino revelam as suas distintas recompensas económicas no mercado de trabalho (Figura 11) ${ }^{13}$.

\section{As posições profissionais típicas dos doutorados da NOVA}

Recorrendo a uma análise de clusters hierárquica, procurámos combinar as várias características da situação profissional dos doutorados que analisámos separadamente numa única tipologia de situações profissionais um ano após a graduação ${ }^{14}$ e esta análise permitiu criar três tipos de posições profissionais significativamente distintas entre si. Com base nessas distinções que surgem sistematizadas na tabela 2, foram atribuídas designações a estes três tipos: "estável", "instável" e "desajustada". Foi posteriormente acrescentado um outro grupo a esta tipologia que 
Tabela 2 Tipologia de situações profissionais dos doutorados da NOVA entre 2010 e 2015

\begin{tabular}{|c|c|c|c|c|}
\hline & \multicolumn{4}{|c|}{ Tipos de situações profissionais } \\
\hline & Instável & Estável & Desajustada & Outsider \\
\hline Contingente feminino (\%) & 59.1 & 52.3 & 70.4 & 59.5 \\
\hline Média etária (Anos) & 36.3 & 44.7 & 40.1 & 42.1 \\
\hline Trabalhou durante o curso (\%) & 53.6 & 86.9 & 65.7 & 33.8 \\
\hline Trabalha fora de Portugal (\%) & 6.9 & 2.3 & 5.6 & \\
\hline Ajustamento profissional (\%) & 100 & 100 & 0 & \\
\hline Contrato temporário (\%) & 100 & 0 & 55.6 & \\
\hline Cargo de chefia (\%) & 29.6 & 52.8 & 31.5 & \\
\hline Média do rendimento mensal líquido (euros) & 1556.1 & 1774.3 & 1480.8 & \\
\hline \multirow{4}{*}{$\begin{array}{l}\text { Trabalha no setor público de emprego (\%) } \\
\text { Desempregados (\%) } \\
\text { Inativos (\%) } \\
\text { Peso no total de doutorados (\%) }\end{array}$} & 78.7 & 80.1 & 69.4 & \\
\hline & & & & 45.9 \\
\hline & & & & 54.1 \\
\hline & 44.8 & 27.1 & 16.6 & 11.4 \\
\hline
\end{tabular}

reúne os doutorados que não se encontravam no mercado de trabalho e que por esse facto surge designado por "outsider" (Tabela 2).

Na tabela 2 podemos verificar que o tipo de situação profissional mais comum é o instável (44,8\%). Tratam-se de doutorados exclusivamente com empregos temporários, mas considerados ajustados à sua área de formação, de entre os quais se destacam os docentes de ensino superior em período probatório ou os investigadores com bolsas de investigação. Face ao conjunto dos doutorados, os instáveis são mais jovens, aqueles que menos procuraram conciliar os seus estudos com o trabalho e os que mais trabalham fora de Portugal. Em segundo lugar no que concerne à frequência, surgem os doutorados em situações estáveis $(27,1 \%)$ que aliam a segurança contratual à total adequação entre profissão e área de formação, sendo também o grupo melhor remunerado e mais próximo de cargos de chefia. Este grupo é o menos jovem, o que mais trabalhou enquanto realizava o doutoramento e aquele que menos se encontra no estrangeiro a trabalhar. O tipo desajustado inclui uma parcela reduzida de doutorados (16,6\%) que se encontra numa situação de desajustamento profissional e com níveis de trabalho temporário maioritários. Este grupo de doutorados possui salários médios mais reduzidos que os restantes grupos, sendo também o que mais se inscreve no setor privado. Em termos etários, assim como no que respeita à parcela de trabalhadores estudantes e de emigrantes, os desajustados encontram-se sempre num ponto médio entre os dois anteriores tipos de situação profissional. Por último, os doutorados outsiders representam uma parcela exígua $(11,4 \%)$, composta por doutorados economicamente inativos $(54,1 \%)$ ou à procura de um emprego $(45,9 \%)$ com uma média etária pouco juvenil e com os mais baixos níveis de trabalho durante o curso - acrescente-se que cerca de $1 / 3$ destes doutorados está inscrito em novas formações académicas. É também 


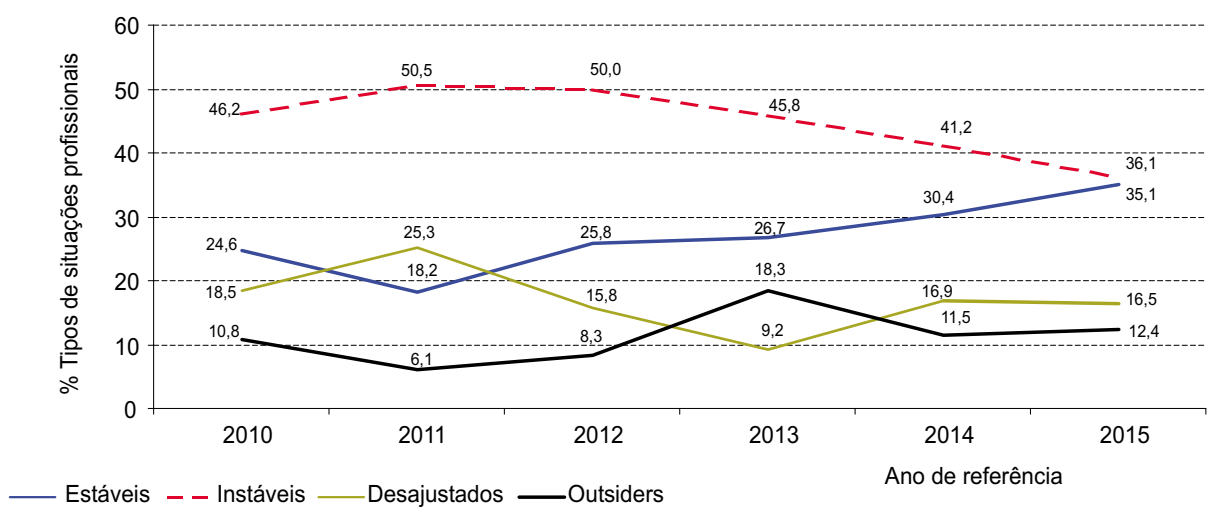

Figura 12 Tipologia situações profissionais entre os doutorados da NOVA de 2010 a 2015 (\%) Fonte: OBIPNOVA.

importante notar que o contingente feminino aumenta sobremaneira nos tipos profissionais menos capitalizados - instável e desajustado - , o que poderá constituir indício da desigualdade de género em desfavor das mulheres que perpassa o mundo do trabalho português (Casaca, 2012).

Entre 2010 e 2015 a distribuição dos doutorados pelos vários tipos de situação profissional altera-se bastante, mas evolutivamente assume contornos inequivocamente positivos, uma vez que os doutorados em situação estável aumentam progressivamente enquanto os instáveis e desajustados sofrem uma quebra acentuada. Por seu turno, os doutorados outsiders constituem sempre situações pouco frequentes ao longo dos 6 anos sob escrutínio, apesar do seu crescimento assinalável no ano de 2013, justamente aquele em que a crise do emprego mais se fez sentir entre doutorados (Figura 12).

Por recurso a uma análise categorial de regressão (via Optimal Scaling), procurámos aferir se a distribuição dos doutorados pela tipologia de situações profissionais se relaciona com algumas das variáveis que, de acordo com a literatura sobre inserção profissional de graduados do ensino superior em Portugal, assumem especial importância no momento de transição da academia para o mundo do trabalho. Assim, considerando a globalidade dos dados, essa tipologia foi tomada enquanto variável dependente numa análise que considera como variáveis independentes, ou preditores, a idade, o sexo, ter trabalhado durante o curso, a área de formação académica e o ano a que se referiam os dados (Tabela 3) ${ }^{15}$.

Os resultados desta análise permitem comprovar que o sexo dos doutorados não está correlacionado com a tipologia de situações profissionais, não obstante a 
Tabela 3 Regressão categorial via optimal scaling

\begin{tabular}{lccccc}
\hline Preditores & $\begin{array}{c}\text { Erro } \\
\text { estandardizado }\end{array}$ & $\begin{array}{c}\text { Graus de } \\
\text { liberdade }\end{array}$ & $F$ & Significância & $\begin{array}{c}R^{2} \text { part } \\
\text { (Importância) }\end{array}$ \\
\hline Idade & 0.0371878 & 1 & 40.051 & 0 & 0.388 \\
Sexo & 0.0353363 & 1 & 0.312 & 0.388 & 0.008 \\
Trabalhou durante o curso & 0.0368724 & 1 & 42.544 & 0 & 0.346 \\
CNAEF & 0.0356004 & 5 & 26.754 & 0 & 0.205 \\
Ano civil & 0.0354546 & 5 & 17.861 & 0 & 0.053 \\
\hline
\end{tabular}

Variável dependente: Tipologia de Situações Profissionais.

clara sobrerepresentação de mulheres nos tipos profissionais menos qualificados. Por outro lado, sobressai a importância preditiva da idade $\left(R^{2}\right.$ part $\left.=38.8 \%\right)$ e de ter trabalhado durante o curso $\left(R^{2}\right.$ part $\left.=34.6 \%\right)$, atestando que os percursos escolares mais lineares e dedicados resultam em inserções profissionais mais complexas e instáveis. Apesar de significante, a influência da área de formação dos doutorados $\left(R^{2}\right.$ part $\left.=20.5 \%\right)$ é bastante menor, o que reforça o papel da idade e experiência profissional no percurso de inserção profissional dos doutorados, não obstante as diferenças quantitativas e qualitativas no emprego entre as várias áreas científicas. Por outro lado, a importância preditiva do ano é apenas residual $\left(R^{2}\right.$ part $\left.=5.3 \%\right)$, o que contribui para se afirmar que a crise económica teve pouco impacto nos percursos profissionais destes doutorados.

\section{Notas conclusivas}

À guisa de conclusão convém sistematizar as respostas para as questões inicialmente colocadas, assim como destacar outros focos de interesse e prolongamentos que assomaram ao longo desta análise aos graduados da NOVA entre 2010 e 2015.

Desde logo, os dados analisados permitiram verificar que os doutorados se têm tornado cada vez mais jovens e exclusivamente dedicados aos seus estudos, tal como aliás sucede com os seus colegas licenciados ou mestres, ou seja, as carreiras académicas revelam-se progressivamente mais longas, lineares e dedicadas. Trata-se de um facto particularmente relevante se considerarmos que a conclusão dos estudos e o acesso a um emprego são dois dos marcadores simbólicos por excelência da passagem para a idade adulta, a par com a saída de casa dos pais e a formação de uma (nova) família (Mauritti, 2002). Assim, o crescente grupo de novos doutorados que faz o seu percurso de vida apenas na esfera do ensino e que o termina já com mais de 30 anos poderá enfrentar uma crónica descronologização (Pais e Ferreira, 2010) das tradicionais temporalidades biográficas (Guillemard, 2005). 
Trata-se de uma hipótese que importa explorar em análises subsequentes por ser expectável que não se coloque apenas no caso dos doutorados da NOVA, constituindo uma faceta pouco explorada da individualização e pluralização dos percursos de vida na modernidade (Aboim, 2010).

No momento de transição para o mercado de trabalho a vantagem de possuir um doutoramento surge inequívoca entre os graduados da NOVA, quer no que concerne às oportunidades de emprego, quer à qualidade desses empregos, quer ainda ao refúgio que propicia relativamente às flutuações criadas pelo agravamento e desagravamento da situação económica durante o período em análise. Este efeito diferenciador surge flagrante face aos licenciados e menos notório quando comparado com a situação dos mestres, porém a sua importância sobressai na relevância estatística que reveste as diferenças entre ciclos de ensino na maioria dos indicadores e dos anos em análise, mesmo no que concerne à segurança dos vínculos contratuais. Com efeito, verificou-se que a precariedade contratual entre recém-doutorados, ainda que dominante, reduz progressivamente ao longo dos anos em análise, o que contrasta sobremaneira com o que sucede com os restantes graduados da NOVA e, acrescente-se, também no conjunto dos jovens graduados em Portugal e na UE.

Entre os doutorados que estão empregados sobressai a sua estreita ligação com a produção de conhecimento no setor público, especialmente através das áreas da docência no ensino superior e da investigação científica e, cada vez menos, em posições reguladas por vínculos contratuais temporários. Esta aliança reforça-se progressivamente, não obstante a redução dos doutorados com bolsas de pós-doutoramento ou de investigação nas coortes mais recentes. Para além disso, constatou-se um limitado contributo destes doutorados para a disseminação de conhecimento, no sentido em que apenas uma parcela diminuta se inscreve no tecido empresarial privado, mas também porque são raros os percursos de inserção profissional que levem até cargos na administração pública. Não sendo expectável que o investimento público nas instituições de ensino superior e nas carreiras científicas aumente, este fluxo contínuo e crescente de novos doutorados para essas profissões na esfera pública pode constituir uma séria ameaça para os seus percursos profissionais num futuro próximo. Afirma-se portanto necessário promover a diversificação das vias de inserção profissional dos recém-doutorados, especialmente procurando aproximá-los de posições no mundo do trabalho que se associem à transferência de conhecimento, nomeadamente e tal como sugerem Cardoso, Tavares e Sin (2019), através do desenvolvimento quantitativo e qualitativo dos doutoramentos em ambiente empresarial.

Verificou-se, por último, que a maior qualidade da inserção profissional destes doutorados depende mais da sua (maior) idade e de terem trabalhado 
durante o curso, do que da área académica de formação ou género como sucede em análises que agrupam os graduados do ensino superior. Tal sugere que as cada vez mais frequentes trajetórias académicas lineares e dedicadas até ao doutoramento são mais propensas a inserções profissionais mais complexas e precárias, bem como que as diferenças de género se matizam entre os doutorados empregados, provavelmente também em resultado da sua aliança ao emprego público onde os princípios igualitários do código de trabalho português são previsivelmente melhor aplicados. Trata-se de uma particularidade face aos fatores de clivagem usualmente identificados para o conjunto dos graduados do ensino superior que importa monitorizar atentamente dada a sua progressiva feminização.

Ainda que as conclusões desta análise não permitam qualquer extrapolação, sustentam uma discussão mais informada sobre os percursos de inserção profissional de recém-doutorados e de como estes se entrecruzam com a produção e transmissão de conhecimento. No entanto, as vincadas diferenças encontradas nos perfis educacionais e profissionais entre licenciados, mestres e doutorados da NOVA, reificam a importância de considerar estes diferentes níveis académicos individualmente quando se pretende investigar os percursos de inserção profissional de graduados, assim como de incentivar a criação de fontes informação que o permitam fazer com alcance nacional e internacional. Perante a obrigatoriedade de concluir o $12^{\circ}$ ano de escolaridade em Portugal e a vulgarização dos cursos de mestrado, é expectável que o doutoramento se consolide enquanto fator educacional diferenciador no mercado de trabalho e, portanto, quaisquer análises com este detalhe assumem também especial importância no âmbito das políticas públicas de emprego e na gestão da procura e oferta de cursos superiores.

\section{Notas}

Por decisão pessoal, os autores do texto escrevem segundo o novo acordo ortográfico.

1 Em 2015, considerando a média dos 28 Estados membros da UE, o número de novos doutorados por cada 1000 indivíduos com idades entre os 25 e 34 anos ascende a 2,01, enquanto nos Estados Unidos da América se queda por 1,55 e no Japão não ultrapassa os 1,10. Entre o conjunto europeu, Portugal coloca-se na $12^{a}$ posição com 1,90 novos doutorados por 1000 indivíduos neste intervalo etário, a Eslovénia ocupa a $1^{\mathrm{a}} \mathrm{com}$ 3,55 e Malta assume a $28^{\mathrm{a}}$ com 0,48 (UE, 2018).

2 O Observatório da Ciência e do Ensino Superior (OCES) realizou a primeira inquirição, ainda em 2004, a todos os doutorados residentes em Portugal, a qual serviu também de "inquérito piloto ao $\mathrm{CDH}$, preparando Portugal para esta nova operação estatística" (Gonçalves, Duarte, Saleiro, Lopes e Rolão, 2006, p. 77). 
Em nenhum dos anos em observação se registam, de acordo com o teste de Qui-quadrado, associações estatisticamente significativas entre sexo e ciclo de estudos. O teste One-way Anova, realizado para a globalidade dos anos em análise e uma vez garantida a homogeneidade de variâncias nas variáveis em análise através do teste de Leverne, indica que a idade média dos graduados difere significativamente entre os três ciclos de ensino $(\mathrm{F}=1429,904, \mathrm{p}>0,001)$. As comparações posteriores entre pares de médias através do teste post hoc de Tukey revelam que os doutorados são significativamente menos jovens que os licenciados (Dif. Médias=14,407, p >0,001) e os mestres (Dif. Médias=9,924, p >0,001).

5 O teste do Qui-quadrado identifica uma associação estatisticamente significativa entre o ciclo de estudos e ter trabalhado durante o curso nos anos de $2010\left(\chi^{2}=22,539\right.$; $\mathrm{gl}=2 ; \mathrm{p}<, 001) ; 2012\left(\chi^{2}=47,665 ; \mathrm{gl}=2 ; \mathrm{p}<, 001\right) ; 2013$ ( $\left.\chi^{2}=28,138 ; \mathrm{gl}=2 ; \mathrm{p}<, 001\right) ; 2014$ $(\chi 2=61,890 ; \mathrm{gl}=2 ; \mathrm{p}<, 001)$; e $2015\left(\chi^{2}=14,332 ; \mathrm{gl}=2 ; \mathrm{p}=0,001\right)$.

6 O teste do Qui-quadrado identifica uma associação estatisticamente significativa entre o ciclo de estudos e a área científica de formação em todos os anos: 2010 $\left(\chi^{2}=277,657 ; \mathrm{gl}=10 ; \mathrm{p}<, 001\right) ; 2011\left(\chi^{2}=383,038 ; \mathrm{gl}=12 ; \mathrm{p}<, 001\right) ; 2012\left(\chi^{2}=584,766 ; \mathrm{gl}=12\right.$; $\mathrm{p}<, 001) ; 2013$ ( $\left.\chi^{2}=542,816 ; \mathrm{gl}=12 ; \mathrm{p}<, 001\right) ; 2014\left(\chi^{2}=601,692 ; \mathrm{gl}=12 ; \mathrm{p}<, 001\right) ;$ e 2015 $\left(\chi^{2}=469,503 ; \mathrm{gl}=12 ; \mathrm{p}<, 001\right)$.

7 O teste do Qui-quadrado identifica uma associação estatisticamente significativa entre o ciclo de estudos e a situação perante a atividade (composta por três categorias: empregado, desempregado e inativo $)$ em todos os anos: $2010\left(\chi^{2}=198,429 ; \mathrm{gl}=4\right.$; $\mathrm{p}<, 001) ; 2011\left(\chi^{2}=313,340 ; \mathrm{gl}=4 ; \mathrm{p}<, 001\right) ; 2012\left(\chi^{2}=538,734 ; \mathrm{gl}=4 ; \mathrm{p}<, 001\right) ; 2013$

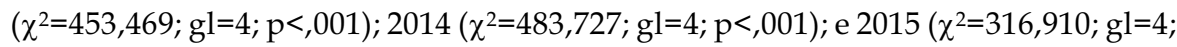
$\mathrm{p}<, 001)$.

8 O teste do Qui-quadrado identifica uma associação estatisticamente significativa entre o ciclo de estudos e trabalhar fora de Portugal nos anos de 2011 ( $\chi^{2}=11,959$; gl=2; $\mathrm{p}=0,003)$ e $2012\left(\chi^{2}=10,928 ; \mathrm{gl}=2 ; \mathrm{p}=0,004\right)$.

9 O teste do Qui-quadrado identifica uma associação estatisticamente significativa entre o ciclo de estudos e o ajustamento profissional em $2011\left(\chi^{2}=26,306 ; \mathrm{gl}=2 ; \mathrm{p}<, 001\right)$;

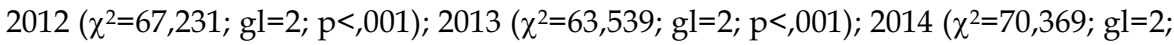
$\mathrm{p}<, 001)$; e 2015 ( $\left.\chi^{2}=48,978 ; \mathrm{gl}=4 ; \mathrm{p}<, 001\right)$.

10 O teste do Qui-quadrado identifica uma associação estatisticamente significativa entre o ciclo de estudos e ter um emprego temporário em todos os anos: $2010\left(\chi^{2}=50,329 ; \mathrm{gl}=2\right.$;

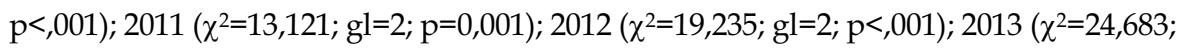

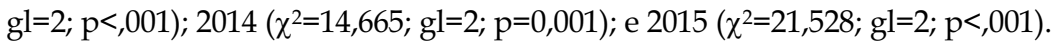

11 O teste do Qui-quadrado identifica uma associação estatisticamente significativa entre o ciclo de estudos e trabalhar no setor público em todos os anos: $2010\left(\chi^{2}=108,694 ; \mathrm{gl}=2\right.$;

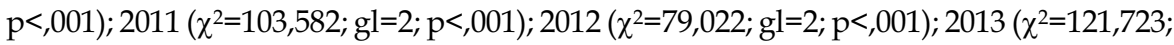

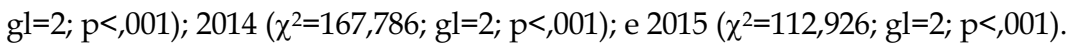

12 O teste do Qui-quadrado identifica uma associação estatisticamente significativa en-

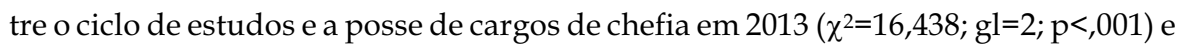
$2015\left(\chi^{2}=15,593 ; \mathrm{gl}=2 ; \mathrm{p}<, 001\right)$. 
13 O teste One-way Anova, realizado para a globalidade dos anos em análise e uma vez garantida a homogeneidade de variâncias nas variáveis em análise através do teste de Leverne, indica que o rendimento mensal líquido dos graduados difere significativamente entre os três ciclos de ensino $(\mathrm{F}=585,290, \mathrm{p}<0,001)$. As comparações posteriores entre pares de médias através do teste post hoc de Tukey revelam que os doutorados são significativamente melhor remunerados que os licenciados (Dif. Médias=779,555, $\mathrm{p}<0,001$ ) e os mestres (Dif. Médias=455,266, p>0,001).

14 Esta análise foi realizada por recurso ao método de Ward para agregação de casos em grupos (de acordo com um critério de maximização da homogeneidade dentro dos grupos). Devido à existência de "não respostas" em algumas das variáveis em teste 54 doutorados não foram classificados nesta tipologia, o que representa 7,7\% do total de 703 casos em análise.

15 O ajustamento deste modelo estatístico é de 20,6\% (Adjusted R2 = 0,2064).

\section{Referências}

Aboim, S. (2010). Cronologias da vida privada. Em J. M. Pais, e V. S. Ferreira (Eds.), Tempos e transições de vida: Portugal ao espelho da Europa (pp. 107-148). Lisboa, Portugal: ICS.

Allen, J., e Velden, R. (2007). The flexible professional in the knowledge society. Maastricht, Holanda: Research Centre for Education and the Labor Market.

Alves, M. (2010). Ensino superior e inserção profissional - Uma análise comparativa de percursos de licenciados. Configurações, 7, 47-64.

Alves, M., Morais, C., e Chaves, M. (2017). Employability of higher education graduates in Portugal: Trends and challenges in the beginning of the 21st century. Forum Sociológico, (31), 9-19.

Alves, M., Morais, C., e Chaves, M. (no prelo). A inserção profissional de licenciados e mestres: Efeitos paradoxais da feminização do ensino superior em tempos de incerteza. Sociologia Problemas e Práticas. Aceite para publicação em 27 de Maio de 2019.

Cairns, D., Cuzzocrea, V., Briggs, D., e Veloso, L. (2017). The consequences of mobility: Reflexivity, social inequality and the reproduction of precariousness in highly qualified migration. Basingstoke, Reino Unido: Palgrave Macmillan.

Cardoso, J. L., Escária, V., Ferreira, V. S., Madruga, P., Raimundo, A., e Varanda, M. (2012). Empregabilidade e ensino superior em Portugal. Lisboa, Portugal: A3ES Readings.

Cardoso, S., Carvalho, T., e Videira, P. (2018). Is it still worth working in academia? The views from Portuguese academics. Higher Education Policy Online, 1-17.

Cardoso, S., Tavares, O., e Sin, C. (2019). Can you judge a book by its cover? Industrial doctorates in Portugal. Higher Education, Skills and Work-Based Learning. DOI: 10.1108/HESWBL-05-2018-0056.

Casaca, S. (2012). Mercado de trabalho, flexibilidade e relações de género: Tendências recentes. Em S. Casaca (Ed.), Mudanças laborais e relações de género. Novos vetores de desigualdade (pp. 9-50). Lisboa, Portugal: Almedina. 
Chaves, M., e Morais, C. (2014). Nivelação e desigualdade na inserção profissional de diplomados do ensino superior. Sociologia, Problemas e Práticas, 76, 87-108.

Chaves, M., Morais, C., e Nunes, J. (2009). Os diplomados do ensino superior perante o mercado de trabalho: Velhas teses catastrofistas, aquisições recentes. Fórum Sociológico, (19), 83-98.

Costa, A., e Caldas, J. (2013). A UE e Portugal entre os resgates bancários e a austeridade. Em Observatório das Crises e das Alternativas (Ed.), A anatomia da crise: Identificar os problemas para construir alternativas (pp. 72-107). Coimbra, Portugal: CES.

Cotrim, R., e Duarte, A. (2015). Inquérito aos doutorados 2012: Principais resultados. Lisboa, Portugal: DGEEC.

Direção-Geral de Estatísticas da Educação e Ciência (DGEEC). (2016). O perfil do aluno 2014/2015. Lisboa, Portugal: DGEEC.

Direção-Geral de Estatísticas da Educação e Ciência (DGEEC). (2017). Inquérito aos doutorados 2015 (CDH15) - Sumário estatístico. Disponível em http:/ / www. dgeec.mec.pt/np4/208/\%7B\$clientServletPath\%7D/?newsId=114\&fileName=Sum arios_Estatisticos_CDH151.xlsx.

Direção-Geral de Estatísticas da Educação e Ciência (DGEEC). (2019). Indicadores relativos ao ensino superior no século XXI - Diplomados, por nível de formação. Disponível em http://w3.dgeec.mec.pt /dse/eef/indicadores/index5.asp.

Enders, J. (2004). Research training and careers in transition: A European perspective on the many faces of the Ph.D. Studies in Continuing Education, 26(3), 419-429.

Ferreira, V. (2017). Os jovens perante o (des)emprego, o trabalho e o futuro nos anos de austeridade. Em V. S. Ferreira, M. Lobo, J. Rowland, e E. Sanches (Eds.), Geração milénio? Um retrato social e político (pp. 39-78). Lisboa, Portugal: ICS.

Fischer, S. (2018). La mission insertion professionnelle des doctorants en SHS: Tensions et enjeux autour des valeurs professionnelles dans les discours des enseignants-chercheurs. Éducation et socialisation, 47, 1-20.

Gabinete de Planeamento, Estratégia, Avaliação e Relações Internacionais (GPARI). (2009). O perfil dos doutorados - Inquérito aos doutorados 2006. Lisboa, Portugal: GPARI.

Gabinete de Planeamento, Estratégia, Avaliação e Relações Internacionais (GPARI). (2011). O perfil dos doutorados - Inquérito aos doutorados 2009. Lisboa, Portugal: GPARI.

Gomes, R. (2015). Fuga de cérebros. Lisboa, Portugal: Bertrand.

Gonçalves, I., Duarte, J., Saleiro, H., Lopes, R., e Rolão, F. (2006). A situação académica e profissional dos recém-doutorados em Portugal - Resultados do inquérito aos doutorados 2004. Lisboa: Observatório da Ciência e Ensino Superior.

Guillemard, A. (2005). The advent of a flexible life course and the reconfigurations of welfare. Em J. Andersen, e A. Guillemard (Eds.), The changing face of welfare: Consequences and outcomes from a citizenship perspective (pp. 55-73). Bristol: Policy Press.

Horta, H., e Hasanefendic, S. (2015). Young doctorates in a fast-changing higher education system. Em M. Yudkevich, P. ltbach, e L. Rumbley (Eds.), Faculty in the twenty-first century: International perspectives (pp. 201-226). Albany: State University of New York. 
Jones, M. (2013). Issues in doctoral studies-forty years of journal discussion: Where we been and where are we going. International Journal of Doctoral Studies, 8, 83-104.

Kyvik, S., e Olsen, T. (2012). The relevance of doctoral training in different labour markets. Journal of Education and Work, 25(2), 205-224

Marques, A., e Alves, M. (Orgs.) (2010). Inserção profissional de graduados em Portugal (Re)Configurações teóricas e empíricas. Braga, Portugal: Húmus.

Mauritti, R. (2002). Padrões de vida dos estudantes universitários nos processos de transição para a vida adulta. Sociologia, Problemas e Práticas, 39, 85-116.

Monteiro, S., Almeida, L., e Aracil, A. (2016). Graduates' perceptions of competencies and preparation for labour market transition: The effect of gender and work experience during higher education. Higher Education, Skills and Work-Based Learning, 6(2), 208-220.

Observatório de Empregabilidade do IST (OEIST). (2013). Empregabilidade dos diplomados de $3^{\circ}$ Ciclo: Situação atual e impacto da formação no contexto profissional. Lisboa, Portugal: OEIST.

Observatório de Inserção Profissional de Diplomados da NOVA (OBIPNOVA). (2017). Percurso de inserção profissional dos licenciados, mestres e doutores da UNL. Lisboa, Portugal: UNL.

Observatório do Percurso Socioprofissional dos Diplomados da Universidade de Aveiro (OPSDUA). (2018). A empregabilidade dos diplomados pela universidade de Aveiro. Aveiro, Portugal: UA.

Pais, J. M., e Ferreira, V. S. (2010). Tempos e transições de vida: Portugal ao espelho da Europa. Lisboa, Portugal: ICS.

Raffe, D. (2014). Explaining national differences in education-work transitions: Twenty years of research on transition systems. European Societies, 16(2), 175-193.

Santos, J., Horta, H., e Heitor, M. (2016). Too many PhDs? An invalid argument for countries developing their scientific and academic systems: The case of Portugal. Technological Forecasting \& Social Change, 113, 352-362.

Theicher, U. (2009). Higher education and the world of work. Roterdão, Holanda: Sense.

União Europeia (UE). (2018). Science, research and innovation performance of the EU. Bruxelas, Bélgica: UE.

Vittorio, N. (2015). European doctoral programs in light of EHEA and ERA. Em A. Curaj, L. Matei, R. Pricopie, J. Salmi, e P. Scott (Eds.). The European higher education area: Between critical reflections and future policies (pp. 545-560). Heidelberg, Alemanha: Springer.

Data de submissão: 27/09/2018 | Data de aceitação: 12/02/2019 